\title{
Epidemiological and molecular mechanisms aspects linking obesity and cancer
}

\author{
Mecanismos epidemiológicos e moleculares \\ que associam obesidade e câncer
}

Felipe Osório-Costa ${ }^{1}$, Guilherme Z. Rocha ${ }^{1}$, Marília M. Dias ${ }^{1}$, José B. C. Carvalheira

\begin{abstract}
About $25 \%$ of cancer cases globally are due to excess weight and a sedentary lifestyle. These results are alarming, as the world knows a pandemy of obesity and, in consequence, insulin resistance. Obesity may increase risk for various cancers by several mechanisms, including increasing sex and metabolic hormones, and inflammation. Here, we present a review of epidemiological and molecular evidences linking obesity and cancer - particularly colorectal, postmenopausal breast, endometrial, pancreatic, high grade prostate, hepatocellular, gallbladder, kidney and esophageal adenocarcinoma. The expected striking increase in the incidence of cancer in the near future related to obesity turns the knowledge of this field of great impact as it is needed to the development of strategies to prevent and treat this disease. Arq Bras Endocrinol Metab. 2009;53(2):213-226.
\end{abstract}

Keywords

Neoplasms; obesity; overweight; insulin resistance

\section{RESUMO}

Aproximadamente $25 \%$ dos casos de câncer são decorrentes do excesso de peso e do modo de vida sedentário. Esses resultados são alarmantes, pois o mundo vive uma pandemia de obesidade e, consequentemente, de resistência à insulina. A obesidade pode aumentar o risco de vários tipos de câncer por diversos mecanismos, incluindo aumento dos hormônios sexuais e metabólicos, e de inflamação. Neste trabalho, apresentamos uma revisão das evidências epidemiológicas e moleculares que relacionam a obesidade ao câncer - em particular aos cânceres colorretal, mamário na pós-menopausa, endometrial, pancreático, prostático avançado, hepatocelular, de bexiga, renal e esofágico. $\mathrm{O}$ aumento esperado da incidência de câncer relacionado à obesidade em um futuro próximo torna o conhecimento dessa área de grande importância, uma vez que este é fundamental para o desenvolvimento de estratégias preventivas e terapêuticas para a doença. Arq Bras Endocrinol Metab. 2009;53(2):213-226.
1 Disciplina de Medicina Interna, Departamento de Clínica Médica, Faculdade de Ciências Médicas da Universidade Estadual de Campinas (FCM-Unicamp), Campinas, SP, Brasil
Correspondence to: José B. C. Carvalheira Departamento de Medicina da Faculdade de Ciências Médicas da Unicamp

Rua Tessalia Vieira de Camargo, 126 13083-970 - Campinas, SP, Brasil carvalheirajbc@uol.com.br

Received in Feb/13/2009 Accepted in Feb/15/2009

Descritores

Neoplasias; obesidade; sobrepeso; resistência à insulina

\section{INTRODUCTION}

Cince the 1980's, the world has been living a striking $\checkmark$ increase in the prevalence of overweight and obesity. This phenomenon has had it's beginning in developed countries, but, nowadays, it is also common to many other populous regions over the world, as Asia and Latin America, and it is becoming a Public Health concern $(1,2)$. By the end of the last millennium, nearly two- thirds of adults in the United States were overweight or obese, and their prevalence continues to increase in this decade (3). The incidence of type 2 diabetes during this same period of time has mirrored the obesity epidemic, and that is presumed to be a direct result of it.

There are epidemiologic studies linking adiposity and the risk of several adult cancers. Investigation of pathophysiological mechanisms and clinical interven- 
tions applied to the process of excess body weight and carcinogenesis has, thus, become an interesting research field. This review outlines the epidemiological and clinical evidence implicating excess body weight both in increased cancer risk and its impact on mortality in certain neoplasias. Some hypothesis explaining these epidemiological observations are explored, specially the metabolic and endocrine effects of obesity, and the alterations that they induce in the production of peptide, steroid hormones and inflammation pathways.

\section{EPIDEMIOLOGY OF ADIPOSITY AND CANCER RISK}

Evidences from epidemiological studies indicate that adiposity contributes to an elevated risk of developing some cancers and may also influence disease outcomes. Both the International Agency for Research on Cancer (IARC) (4) and, more recently, the World Cancer Research Fund (WCRF) (5) have concluded that, among the different cancer sites, this association is positive for esophageal adenocarcinoma, and cancers of the pancreas, colorectum, post-menopausal breast, endometrium and kidney, beyond the evidence of a probable association with risk of gallbladder cancer.

These results were further confirmed to the high prevalent cancers listed above and extended to reveal associations with less common malignancies in a large British cohort, the Million Women Study, and in a multiethnic systematic review and meta-analysis (table 1 ). It is important to observe that this multiethnic analysis found a constant association between body mass index (BMI) and cancer across populations, except for premenopausal breast cancer, in which there has been observed a positive association with increased BMI in AsiaPacific populations, but an inverse association in the other regions $(6,7)$. There are also some other constant similarities in most of the epidemiologic evidences. The effect of BMI on risk differed significantly according to menopausal status (and, by extrapolation, hormonal influences) as follows: increased risk in pre-menopausal women for colorectal cancer and malignant melanoma, while increased risk in post-menopausal women for breast and endometrial cancers (6). As a concern to intergender comparisons, there are differences in associations at some sites, notably colon, rectum and kidney (8).

Table 1. Summary of estimated trend in the relative risk of cancer incidence by type, adapted from two recent large studies $(6,7)$. Data in italic have not reached significance

\begin{tabular}{|c|c|c|c|}
\hline \multirow[b]{2}{*}{ Incident cases } & \multirow{2}{*}{$\begin{array}{c}\text { British cohort } \\
45,037\end{array}$} & \multicolumn{2}{|c|}{ Multiethnic meta-analysis } \\
\hline & & \multicolumn{2}{|c|}{282,137} \\
\hline & Trend in relative risk per $10 \mathrm{~kg} / \mathrm{m}^{2}$ & \multicolumn{2}{|c|}{ Trend in relative risk per $5 \mathrm{~kg} / \mathrm{m}^{2}$} \\
\hline Cancer site & Female & Female & Male \\
\hline Endometrium & 2.89 & 1.59 & NA \\
\hline Oesophageal adenocarcinoma & 2.38 & 1.51 & 1.52 \\
\hline Renal & 1.53 & 1.34 & 1.24 \\
\hline Leukemia & 1.50 & 1.17 & 1.08 \\
\hline Multiple myeloma & 1.31 & 1.11 & 1.11 \\
\hline Non-Hodgkin lymphoma & 1.17 & 1.07 & 1.06 \\
\hline Breast (post-menopausal) & 1.4 & 1.12 & NA \\
\hline Colorectum (pre-menopausal) & 1.61 & NA & NA \\
\hline Colon & NA & 1.09 & 1.24 \\
\hline Rectum & NA & 1.02 & 1.09 \\
\hline Gallblader & NA & 1.59 & 1.09 \\
\hline Prostate & NA & NA & 1.03 \\
\hline Pancreas & 1,24 & 1.12 & 1.07 \\
\hline Ovary & 1,14 & 1.03 & NA \\
\hline Liver & NA & 1.24 & 1.07 \\
\hline Stomach & 0.90 & 1.04 & 0.97 \\
\hline
\end{tabular}




\section{EXCESS BODY WEIGHT AND CANCER OUTCOME}

Given that BMI is consistently associated with cancer risk at several sites, it is not surprising that increased adiposity may have a negative effect on treatment outcome and ultimate survival. Data from a large American cohort published by Calle and cols. (9) was the germinal evidence that obesity may be an unfavorable prognostic factor in patients diagnosed with cancer. The heaviest members of this cohort (those with a BMI index of, at least, 40) had death rates from all cancers combined, and they were $52 \%$ higher for men, and $62 \%$ higher for women, than the rates in men and women of normal weight. These results were recently confirmed by Reeves and cols. (6) in another large British cohort. These observations in human studies are supported by pre-clinical data that observed different outcome in models of cancer. In these studies, they were worse in diet-induced obesity animal models (10), and better in energy restriction ones (11).

\section{OBESITY RELATED CANCERS}

\section{Colorectal cancer}

Obesity has been associated with higher risk of colorectal cancer. However, there are important differences related to gender and sites. The association between BMI and risk for colon cancer is positive in men, $\mathrm{RR}=1.24$, but the evidences are weaker in women, $\mathrm{RR}=1.09(8)$. Further, the association with rectal cancer is also weaker and present only in men, $\mathrm{RR}=1.09$.

There are some hypotheses for this gender difference. One of them is that central adiposity, quite more frequent in men, may have an important role in the pathophysiology underlying the association between abdominal obesity and increased colon cancer risk. This could be expected, once abdominal obesity has been shown to be more strongly associated with metabolic abnormalities than gluteofemoral obesity (12). This hypothesis has been supported by epidemiological evidences that associates increased waist circumference or increased waist-hip ratio with colon cancer risk in men and women, whereas body weight and BMI are associated with colon cancer risk in men but not in women $(13,14)$. By contrast to colon cancer risk, these anthropometric results were not reproduced as risk factor for rectal cancer. These epidemiological data are supported by consistent results that associate insulin resistance and subsequent hyperinsulinemia as risk factors for colon cancer (15).
Increased levels of bioavailable insulin-like growth factor (IGF)-1, which is known to have cancer promoting effects, are related to hyperinsulinemia. In addition, insulin interacts with the axis, by reducing the synthesis of IGF binding proteins (IGFBP) (16). The IGF-1 system has been linked to colorectal malignancy by a convergence of data from epidemiological, clinical and laboratory-based sources (16-18). Recent results have also implicated higher levels of prediagnosis plasma C-peptide and lower levels of prediagnosis plasma IGFBP-1 with increased mortality among patients with surgically resected colorectal cancer (19). These results lead to the hypothesis that circulating insulin and IGFBP-1 are potential mediators of the association between lifestyle factors and mortality after colorectal cancer resection.

In regard to adipose tissue-derived cytokines and hormones, collectively named adipokines, recent results may involve them in tumourigenesis. First, leptin, whose circulating levels are closely related to the amount of adipose tissue and is also related to insulin resistance, has been related to progression of colon cancer in experimental studies (16,20-22). This hormone conveys information to the brain about the size of energy storage and its levels are increased by overfeeding (23). In contrast, energy restriction, a well-established protective factor against cancer (24), decreases this hormone levels $(24,25)$. In light of this evidence, leptin was suggested as a link between obesity and colon cancer. This hypothesis is supported by two case-control studies $(22,26)$ that demonstrated significant associations of leptin with colon cancer risk, but not rectal cancer. By contrast, adiponectin, an adipokine decreased in obesity, is inversely associated with the development of insulin resistance and has a strong anti-inflammatory function (3). There are controversial data relating low plasma adiponectin levels with higher risk of colorectal cancer in men, and there is need to further prospective studies to investigate this association $(27,28)$.

\section{Breast cancer}

The evidence linking obesity to breast cancer risk is dependent on the menopausal status. There is consistent evidence for this association in post-menopausal women, but not in pre-menopausal ones. In fact, there are some registries of a modest reduction in risk among women with elevated BMI, which could be because of a tendency for these women to have anovulatory menstrual cycles and lower levels of circulating steroid hormones - notably of progesterone and estradiol. 
In addition, studies that examined both factors have found that adult weight gain is generally more associated with increase in risk of post-menopausal breast cancer than BMI (29); this could also be an effect of anovulatory menstrual cycles in the young obese women. As regards to breast cancer outcome, BMI $\geq 40 \mathrm{~kg} /$ $\mathrm{m}^{2}$ is associated with higher mortality, $\mathrm{RR}=2.12(9)$. This worse prognosis may be because of true biological effect of adiposity on survival or secondary to delayed diagnosis in heavier women.

As concerns to sex steroids, the higher expression of aromatase, which produces estrogens from androgenic precursors, may have an important role in the pathophysiology underlying the association between post-menopausal breast cancer and cancer risk in obese women (8). There is convincing evidence relating the association of BMI with post-menopausal breast cancer risk to be almost entirely mediated by elevated blood levels of estradiol (30). These analyses also demonstrated that elevated blood concentrations of androgens are associated with increased risk of breast cancer in both pre and post-menopausal women, and, thus, androgens may be potential candidates linking obesity and breast cancer. In contrast to men, testosterone concentrations are positively related with obesity in women (30).

Besides steroids influences, several studies associated hyperinsulinemia, measured as high circulating levels of serum C-peptide, with elevated risk of post-menopausal breast cancer (31-33), although these associations were inconsistent with pre-menopausal breast cancer (32-34). In addition, cohort studies and a meta-analysis support increased IGF-1 levels, an indirect effect of hyperinsulinemia, as a risk factor for pre-menopausal breast cancer $(17,35)$. Furthermore, insulin resistance is an adverse prognostic factor for breast cancer (36).

In regard to adipokines, a recent review from VonaDavis and Rose (37) has found inconsistent results related to leptin as breast cancer risk factor. In contrast, two casecontrol studies concurrently reported inverse association between adiponectin and breast cancer; significant for both pre and post-menopausal in one (38), and for postmenopausal women only in the other (39). Clearly, prospective studies are needed to examine the role of obesity biomarkers in the development of breast cancer.

\section{Endometrial carcinoma}

The strongest association, 2.5-3.0-fold increase in risk, between obesity and cancer risk is reported to endo- metrial carcinoma $(6,8)$. The pathophysiology underlying this association, like for breast cancer, is associated to estrogens exposition. This hypothesis is supported by epidemiological studies that have related high levels of plasma estrone and estradiol as risk factors for endometrial cancer risk in post-menopausal women. In addition, hyperandrogenism may also play a central role linking obesity to endometrial cancer risk in pre-menopausal women, as it leads to diminished levels of progesterone and continuous anovulation. The hypothesis is that lack of progesterone promotes unopposed estrogen exposition and continuous proliferation stimulus to endometrial cell lines, which may increase the risk of endometrial cancer, whereas, in post-menopausal, excess weight may continue to increase the risk primarily through elevated plasma levels of bioavailable estrogens, and secondary to higher expression of aromatase, in the absence of ovarian progesterone synthesis. Furthermore, besides a rise in estrogens and androgens, excess weight leads to a decrease in plasma sex hormone-binding globulin (40). In a multicenter prospective study in post-menopausal women (41), circulating estrogens and androgens were found to be positively associated with endometrial cancer risk, and an inverse association was reported for sex hormonebinding globulin.

With regard to insulin resistance, it was speculated that elevated estrogens and low progesterone promote increase in IGF-1 bioactivity within endometrial tissue, resulting from estrogen-induced IGF-1 synthesis and reductions in IGFBP-1, leading to the development and growth of endometrial tumours (40). In addition, biomarkers of hyperinsulinemia, as C-peptide, have been shown to be associated with increased endometrial cancer risk (42).

\section{Renal cancer}

There are several evidences that link obesity as a risk factor for renal cell cancer $(12,43)$. Most of them found a dose-response relationship with increasing weight or BMI (44). However, few studies have observed that fat distribution does not predict renal cell cancer risk beyond adiposity in general (45). As regards to gender, there is an unexplained difference with stronger association in women than in men (44).

Hypertension and diabetes, both of which are risk factors for renal cell cancer, are also associated with obesity $(12,46)$. However, some evidence suggested that obesity 
increases the risk of renal cell cancer even independently of blood pressure levels, indicating that hypertension and obesity might influence renal cell cancer through different mechanisms (12).

The pathophysiology underlying the association of obesity and renal cell cancer remains unclear. Very recently, lower adiponectin levels were observed in individuals with renal cell cancer when compared with healthy controls (47). There is clearly a need for additional studies of this issue with a larger number of patients.

\section{Esophageal and gastric carcinoma}

There is a marked change in esophageal and gastric carcinomas epidemiology. Whereas the incidence rates of esophageal adenocarcinoma and gastric cardia have risen in recent decades, they remained stable for esophageal squamous cell carcinoma and have declined steadily for noncardia gastric adenocarcinoma (48). This rise in incidence has partly been attributed to the rise in the prevalence of obesity. Some evidence from cohorts and meta-analysis have recently confirmed the association between obesity and risk of esophageal adenocarcinoma $(6,7,49)$. Regarding the risk for gastric cardia adenocarcinoma in this analysis, a high BMI was weakly associated with the risk of cardia adenocarcinoma $(R R=1.5)$. Recently, these results were reinforced by a large American cohort, which has found an increased risk for gastric cardia adenocarcinoma for people with BMI $\geq 35 \mathrm{~kg} /$ $\mathrm{m}^{2}$. In contrast, there has not been found any association with gastric non-cardia adenocarcinoma (50).

Thus, there is impressive evidence to link obesity as a risk factor for esophageal and gastric cardia cancer. However, BMI does not explain the intergender differences found in the incidence rates of these cancers, which are more frequent in white men than in women. One hypothesis is that abdominal obesity could explain this discordance. A recent case-control study examined the distribution of obesity as a risk factor for these types of cancer and has found strongly association between elevated abdominal diameter and increased risk of esophageal adenocarcinoma. However, this association was not confirmed with the risk of gastric cardia adenocarcinomas (51). Further prospective studies are necessary to confirm this hypothesis.

At present, Barrett's esophagus, characterized by replacement of squamous epithelium with columnar epithelium, is the most common cause of esophageal adenocarcinoma. The pathophysiology of Bar- rett's esophagus involves gastroesophageal reflux and esophagitis (52). Further, obesity is related to esophagitis, and this association is not present only in symptomatic gastroesophageal reflux obese individuals. The exact role that obesity plays within these processes remains to be defined.

\section{Pancreatic carcinoma}

For some time, there was controversy between the link of obesity and pancreatic carcinoma. Early case-control studies have found weak association, but this is believed to have been biased because of high mortality or reliance on proxy interviews (53). A considerable number of prospective studies and meta-analysis have examined this subject during the last years $(9,54)$, and have shown positive results (13). Recently, this results were reinforced by The Women's Health Initiative in The United States, which has found a $70 \%$ excess risk of pancreatic cancer for women in the highest quintile of waist-to-hip ratio compared with women in the lowest quintile (55).

Several evidence implicates hyperinsulinemia and hyperglycemia in the pathophysiology of pancreatic cancer (56). However, as it matters to IGF axis, a nested casecontrol study within four large cohort studies has not found associations between pre-diagnostic plasma levels of IGF-1, IGF-2 and IGFBP-3 and pancreatic cancer risk (57). The exact role that obesity and insulin resistance play within these processes remains to be defined.

\section{Prostate cancer}

Epidemiological evidence is conflicting and has failed to show overall significant associations between obesity and the risk of prostate cancer (4), although a meta-analysis has suggested a weak significant positive association, with an estimated increase in prostate cancer risk of 1.05 per $5 \mathrm{~kg} / \mathrm{m}^{2}(58)$. However, concerning to prostate cancer outcomes, there is convincing evidence which indicates that obese men with prostate cancer are more likely to have aggressive disease that recurs after radical prostatectomy than non-obese men (59).

Some studies have positively associated high IGF-1 circulating levels with prostate cancer risk, whereas total IGFBP-3 levels were negatively associated (60). There is clearly a need for additional studies of this issue with a larger number of patients to examine the possible effects of obesity and insulin resistance in the pathophysiology of pancreatic cancer. 


\section{Hepatocellular and gallbladder cancer}

The relationship between obesity and risk of gallbladder cancer has recently been investigated in some meta-analyses and cohort studies $(6,7,61)$. Most of them have found a dose-response relationship with increasing weight or $\mathrm{BMI}(\mathrm{RR}=1.15$ in those who were overweight, and $R R=1.66$ in those who were obese). The risk was stronger for women $(\mathrm{RR}=1.88)$ than for men $(\mathrm{RR}=1.35)$. The mechanisms by which obesity may affect gallbladder cancer risk are unclear until now. However, gallstone formation is a major risk factor for this disease and obesity is one of the factors that increase gallstone formation.

Obesity as well as type 2 diabetes are also likely to be risk factors for hepatocellular cancer (62). It is suggested that the increase in the incidence of non-alcoholic fatty liver disease could be the underlying mechanism related to the recent increase in risk for hepatocellular carcinoma, once it may progress to steatohepatitis and cirrhosis.

\section{OTHER CANCERS}

\section{Lung cancer}

Several studies reported an inverse association between obesity and lung cancer, although this data may be secondary to confounding effects of smoking. However, in non-smoking populations, there has not been found any association to link obesity as a risk factor for lung cancer $(9,63)$.

\section{Cervical carcinoma}

The literature is exiguous about the association between obesity and cervical cancer. Overall there is no association reported (28), however an American casecontrol study found an increased risk of adenocarcinomas of the cervix, not extensive to squamous cell carcinomas of the cervix $(\mathrm{RR}=1.6)(64)$. Clearly, additional studies of this issue with a larger number of patients are needed to investigate the association between obesity and cervical cancer.

\section{Ovarian cancer}

A recent systematic review has found a weak (1.3-fold) increase association between obesity and risk for ovarian cancer (65). It was speculated that the association between obesity and weight gain could be restricted to some subtypes of ovarian cancer, but this hypothesis was not confirmed in an Australian case-control study, which has found no association with BMI or weight gain for any of the histological subtypes (66). These results add to the current evidence that obesity increases a woman's risk of developing distinct histological subtypes of ovarian cancer.

\section{Hematopoietic neoplasias}

Several evidence from meta-analysis or large cohort studies have found weak association between obesity and lymphohaematopoietic cancers, including lymphomas, acute and chronic leukaemia (67) and multiple myeloma $(6,7,68)$. Further prospective studies of this issue with a larger number of patients are needed to examine the possible role of obesity as a risk factor for hematopoietic neoplasias.

\section{SUMMARY OF EPIDEMIOLOGICAL EVIDENCE}

After reviewing a large number of literatures, there is currently sufficient evidence that obesity increases the risk for esophageal adenocarcinoma, and cancers of the pancreas, colorectum, post-menopausal breast, endometrium and kidney, beyond evidence of a probable association with risk of gallbladder cancer and hepatocellular cancer. The more recently published studies suggest that obesity may also increase the risk of advanced-stage prostate cancer. It is also suggested that obesity is a risk factor for hematopoietic neoplasias. However, this association may be weak, and there is need for further studies to explore the molecular mechanisms of obesity that could explain these results.

\section{PROPOSED MECHANISMS}

\section{Endogenous hormones}

The association between excess body weight with cancer risk may be explained by alterations in the metabolism of endogenous hormones - including insulin, insulin-like growth factors and sex steroids - which can lead to distortion of the normal balance between cell proliferation, differentiation, and apoptosis. However, the pathophysiological and biological mechanisms underpinning these associations are only starting to be understood.

Tumour genesis occurs as a result of mutations that confer a set of cancer-specific hallmarks, including selfsufficiency in growth signals and evasion of apoptosis. 
Many cancer-causing genes encode protein kinases; indeed, the protein kinase domain is the most commonly found functional domain known in cancer genes. As protein kinases occupy apical positions in signal-transduction cascades, integrate with many other signaling pathways and regulate the activity or abundance of transcription factors, the cellular effects of aberrant protein kinases activity are wide-ranging.

The functional importance of this acquired capability for the manifestation of the disease has been further validated by the approval of tyrosine kinase inhibitors as cancer therapeutics - most notably the ones targeting the BCR Abl and cKIT signaling pathways. The pioneer of the clinical proof-of-concept for tyrosine kinase inhibitors is Imatinib (Gleevec, Novartis) targeting the BCR Abl and cKIT receptor (69). Imatinib has been approved for treating patients with chronic myeloid leukemia and gastrointestinal stromal tumor. Numerous ongoing clinical trials seek to expand the applications of each of tyrosine kinase pathway inhibitors, and dozens of other tyrosine kinase inhibitors are being clinically evaluated.

The same is true for endogenous hormones signaling, which integrates with others signal-transduction cascades to control a variety of processes - including gene expression. Recent years have seen a growing appreciation of the extent to which components of endogenous hormones are remodeled or deregulated in cancer. Whether these changes are drivers that are required to sustain the transformed phenotype remains to be established. In this section, we review the core components of the endogenous hormones signaling systems, focusing on the role of insulin, insulin-like growth factor and sex steroids in one crucial aspect of the cancer phenotype - control of cell proliferation.

\section{Insulin and insulin-like growth factor}

In the early 1990's, McKeown-Eyssen (70) and Giovannucci (71) noted that the risk factors for Westernized cancer were remarkably similar to those for insulin resistance, and suggested that hyperinsulinemia might contribute to cancer development through the growthpromoting effect of elevated levels of insulin. In addition to its importance in glucose homeostasis, it is well established that insulin is a crucial hormone in anabolic processes involved in early growth and development, and may be also a strong mediator of the adverse effect of obesity on cancer prognosis.
Excess body weight, increased plasma triglyceride levels, low levels of physical activity and certain dietary patterns can all favor elevated circulating insulin levels. Chronically increased insulin concentrations reduce the synthesis of IGFBP-1 and 2, resulting in increased levels of free, IGF-1 Bio-Active ${ }^{\circledR}$, and concomitant changes in the cellular environment, that favor tumor development (72). It is also suggested that IGF-1 can synergize with other growth factors to produce enhanced mitogenic effects, and may operate via an endocrine, paracrine or autocrine manner to regulate cell growth, cell survival, cell transformation, and cell differentiation.

Growth hormone $(\mathrm{GH})$ provides the main stimulus for the synthesis of IGF-1 in liver, which is the source of over $80 \%$ of circulating IGF-1, and nutritional energy balance exerts profound and complex effects on the synthesis and biological activity of IGF-1. In type 1 diabetes patients, or in chronically fasting people, the low production of insulin, which causes a reduction in hepatic GH-receptor levels, also results in GH resistance and reduction of IGF-1 blood levels and synthesis. The IGF-1 bioavailability to tissue receptor is also reduced by the increased levels of IGFBP-1 and IGFBP-2. On the other hand, patients with type 2 diabetes, or in over nourished states, have high levels of endogenous insulin and hepatic GH-receptor, producing large amounts of IGF-1 (73). Paradoxically, however, obese people have lower blood levels of IGF-1 than normal-weight, well-nourished individuals (2l). Recent studies have shown a non-linear relationship between IGF-1 and anthropometric indices of adiposity, with the highest levels of IGF-l at a BMI of around $24-27 \mathrm{~kg} / \mathrm{m}^{2}$, and lower levels for men and women in either the lower or higher BMI categories $(74,75)$. An explanation for the low IGF-1 blood levels in obese individuals, despite increased GH sensitivity of liver and other tissues, is that reductions in IGFBP-1 and IGFBP-2 levels increase the negative feedback by free IGF-1 on pituitary GH secretion, resulting in reduced synthesis of IGF-1 and reduced plasma IGF-1 concentrations (21).

Many in vitro and in vivo models provide convincing evidence for a role of IGF- 1 receptor (IGF-1R) in different forms of cancer. Initial in vitro experiments demonstrated that increasing IGF-1 concentrations induced a dose-dependent increase in human breast cancer cell proliferation (76). In vivo models using mutations associated with low IGF-1 levels or reduced ligand levels showed that in vivo tumour growth is influenced by the IGF-1 physiology of the host $(77,78)$. The work 
by Creighton and cols. (79) showed that a pattern of gene expression induced by IGF-1 represents pathways of increased aggressiveness and possibly hormone independence in clinical breast cancers.

As shown in Figure 1, both insulin and IGF-1 activate the important tyrosine kinase growth receptor pathway, insulin receptor (IR) and IGF-1R, respectively, as well as the hybrid IGF-1/IR - all of which are expressed at higher levels in malignant cells and resistant to downregulation typical of receptors in nonmalignant cells exposed to insulin (80). Activation of these receptors results in up-regulation of insulin response substrate-1 (IRS-1), leading to downstream activation of the mitogenic-activated protein (MAP) kinase pathway and the phosphoinositide-3 kinase/Akt (PI3K-Akt) pathway two of the most important signaling cascades frequently deregulated in cancer. In addition, there is accumulating evidence that these pathways may cooperate to promote the survival of transformed cells (81).

PI3K is recruited to the membrane after stimulation by various different growth factors and cytokines. At this site, the enzyme is activated and, in proximity to its lipid substrate, phosphatidylinositol $(4,5)$-bisphosphate $\left[\operatorname{PtdIns}(4,5) P_{2}\right]$, generates $\operatorname{PtdIns}(3,4,5) P_{3}(82)$. The tumor suppressor PTEN acts reversing the action of PI3K, dephosphorylating $\operatorname{PtdIns}(3,4,5) P_{3}$ and is thus an essential suppressor of PI3K signaling. This PTEN function is lost in various advanced-stage cancers. Effector proteins with pleckstrin-homology $(\mathrm{PH})$ domains, such as the AKT/PKB and 3-phosphoinositide-dependent protein kinase 1 ( $\mathrm{PDKl}$ ) protein kinases, utilizes $\operatorname{PtdIns}(3,4,5) P_{3}$ as a docking site. PKB phosphorylates various substrates involved in diverse processes, including cell survival (inactivation of the proapoptotic protein $\mathrm{BAD}$ ), glycogen synthesis (down-regulation of glycogen synthase kinase-3) and gene transcription (FOXO transcription factors) (82); however, PKB also promotes cell and organism growth downstream of PI3K. The mechanisms indicating how the insulin-PI3K-PKB pathway induces growth has recently been clarified by the finding that $\mathrm{PKB}$ phosphorylates and inactivates (83) tuberin - also known as tuberous sclerosis complex 2 (TSC2) -, an inhibitor of cell growth, thereby inactivating the function of the TSC1-TSC2 tumour suppressor complex. TSC1-TSC2 is a complex of the proteins hamartin (TSCl) and tuberin (10) that acts inhibiting GTPaseactivating protein activity of the small GTPase, Rheb (84). Activation of PI3K induced by insulin has been shown to relieve this inhibitory activity (84), resulting in activation of Rheb. This induction of Rheb leads to activation of the mTOR pathway and an mTOR-regulated serine/threonine kinase, S6K.

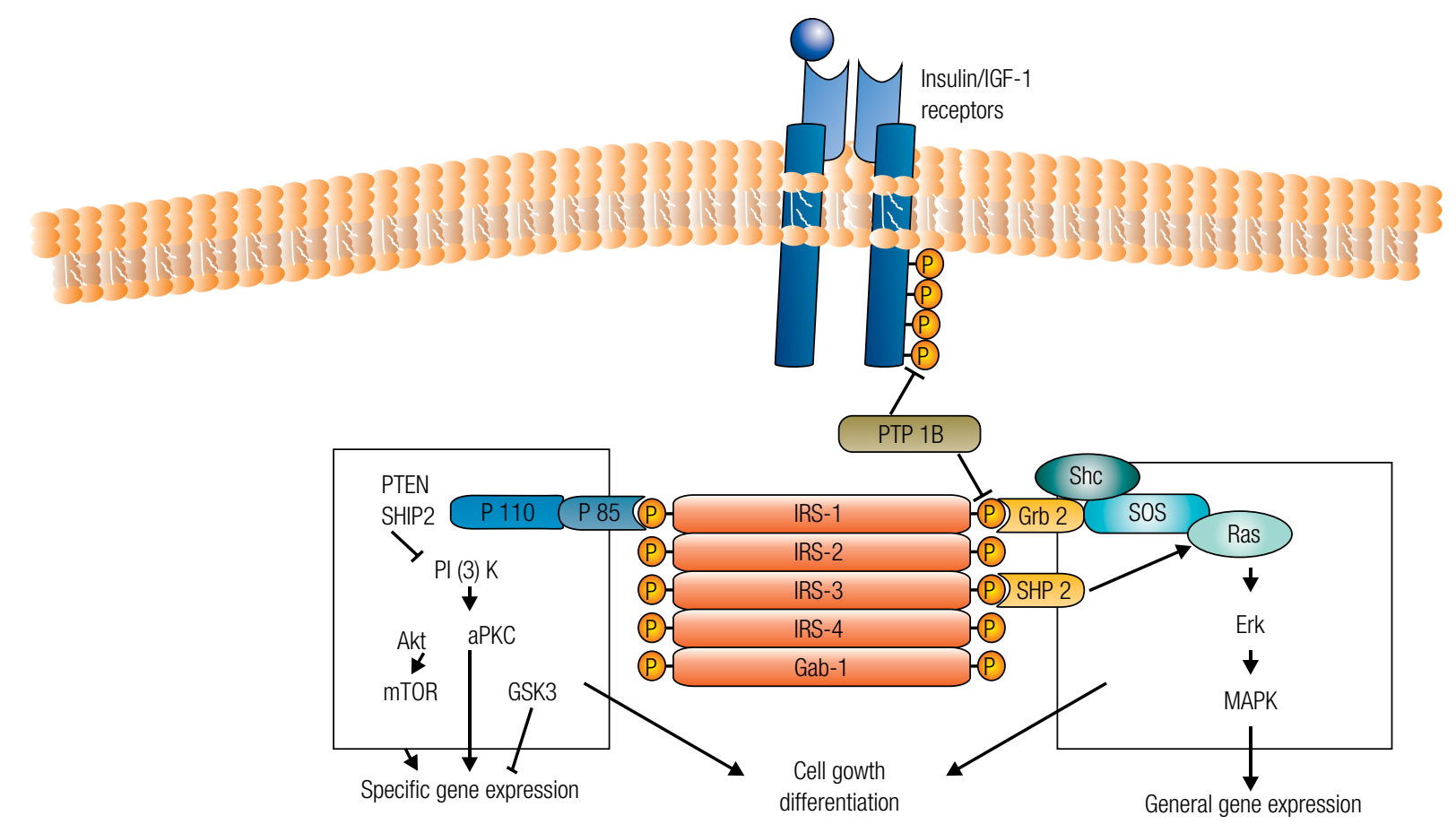

Figure 1. The insulin/IGF-1 receptor is a tyrosine kinase that undergoes autophosphorylation, and catalyses the phosphorylation of cellular proteins such as members of the IRS family and Shc. Upon tyrosine phosphorylation, these proteins interact with signaling molecules through their SH2 domains, resulting in a diverse series of signaling pathways, including activation of PI(3)K and downstream Ptdlns(3,4,5)P3-dependent protein kinases, ras and the MAP kinase cascade. These pathways act in a concerted fashion to coordinate the regulation of vesicle trafficking, protein synthesis, enzyme activation and inactivation, and gene expression. 
The signaling through mTOR pathway is important in ribosome biogenesis and cell growth (85), and its induction after PI3K activation and inactivation of TSClTSC2 by PKB might explain the sequential activation of PKB and S6K by insulin (86). As recently shown, phosphorylation of tuberin by the $\mathrm{p} 90$ ribosomal S6 kinase 1 (Rskl) (87) has a similar inhibitory effect to that of PKB on TSC1-TSC2, this way promoting mTOR signaling; however, phosphorylation of tuberin by 5' AMP-activated protein kinase (AMPK) in response to reduced cellular energy levels might act in the opposite manner to regulate TSC1-TSC2 function positively (88).

Cellular growth is controlled in part by mTORraptor which phosphorylates the hydrophobic motif of S6Kl, activating this kinase. mTOR-raptor also phosphorylates and inhibits 4E-BPs, proteins that inhibit the eIF4E-dependent translation of capped mRNAs (85). Persuasive evidence suggests the existence of a negative-feedback loop that enables the nutrient-sensitive mTOR-raptor pathway, through $\mathrm{S} 6 \mathrm{Kl}$, to desensitize insulin signaling (89). S6Kl mediates the feedback by phosphorylating and inactivating IRS1.

The MAP kinase-Ras-Raf cascade is centrally important in driving tumor cell proliferation. The Ras/Raf/ MEK/ERK cascade couples signals from cell surface receptors to transcription factors, which regulate gene expression. Furthermore, this cascade also regulates the activity of many proteins involved in apoptosis.

The Raf gene family consists of three proteins, termed A-Raf, B-Raf and Raf-1 (C-Raf). Raf is a serine/ threonine $(\mathrm{S} / \mathrm{T})$ kinase, normally activated by a complex series of events, including: (i) interaction with Ras and subsequent recruitment to the plasma membrane; (ii) dimerization of Raf proteins; (iii) phosphorylation / dephosphorylation on different domains; (iv) disassociation from the Raf kinase inhibitory protein (RKIP), and (v) association with scaffolding complexes (e.g., kinase suppressor of Ras, (KSR). Chaperonin proteins such as Bagl, 14-3-3 (90) and heat shock protein 90 (Hsp90) modulates Raf activity (91).

When activated, Raf phosphorylates the serine residue in the activation loop of Mek (MAPKK) (92). The activated Mekl $/ 2$ phosphorylates the MAPK protein, ERK, on adjacent threonine and tyrosine residues. Active ERK phosphorylates multiple cytoplasmic and cytoskeletal proteins (93), including MAPK-activated protein kinases and the family of approximately $90-\mathrm{kDa}$ ribosomal S6 kinases (Rsk). Additionally, active ERK and Rskl/2 translocate to the nucleus, where ERK phosphorylates and activates various transcription factors, such as Spl, E2F, Elk-1 and AP-1 (94). AP-1 is comprised of two short-lived proteins, Jun and Fos, which are the product of immediate early genes (IEGs). This pathway can control various cellular processes such as proliferation, migration and differentiation.

Part of insulin and IGF- 1 action is also mediated by the crosstalk of these pathways with that of the estrogen receptor pathway in breast cells.

\section{Sex steroids}

With regard to sex steroids, adiposity influences the synthesis and bioavailability of the hormones through, at least, three mechanisms. First, adipose tissue expresses a variety of sex-steroid-metabolizing enzymes, like aromatase, that promote the formation of estrogens from androgenic precursors, which are secreted by the gonads or adrenal glands. Adipose tissue is the major site of estrogen synthesis in men and postmenopausal women, with levels of aromatase and circulating levels of estrone and estradiol strongly related to BMI (95).

A second hypothesis is that obesity results in an increase in circulating levels of insulin and IGF-1 bioactivity. Insulin and IGF-1 both inhibit the synthesis of sex hormone-binding globulin (SHBG) - the major carrier protein for testosterone and estradiol in the plasma and may lead to an increase in the amount of unbound sex-steroid available for bioactivity (96). In one study, obese women $\left(\mathrm{BMI}>30 \mathrm{~kg} / \mathrm{m}^{2}\right)$ had average SHBG concentration that was half of that of women with a BMI of $<22 \mathrm{~kg} / \mathrm{m}^{2}(97)$.

SHBG can act directly on breast cancer cells inhibiting the cell proliferation induced by estradiol. Binding of this protein to cell membrane induces the second messenger cAMP on MCF-7 breast cancer cell line (98), and leads to a complete inhibition of estradiolinduced cell proliferation (99). In addition, the preincubation of MCF-7 cells with SHBG before estradiol treatment counteracts the antiapoptotic effect of the hormone (100). Thus, SHBG prevents estradiol action in breast cancer cells, acting as an anti-proliferative factor, loss of which could contribute to tumorigenesis in obese women.

Estradiol (E2) and IGFs also act as mitogens in breast cancer cells trough the activation of ERalpha transcriptional activity. They act together and reciprocally. In addition, insulin at supraphysiologic doses may reproduce the IGF-1 effects on breast cells. It was shown in breast can- 
cer cell lines that E2 interacts with the whole transduction pathways of IGF (101). IGFs act through two membrane receptors: IGF-1R and type 2 receptors (IGF-2R). However, most of the effects of IGFs are mediated by the IGFIR. Activation by the ligand leads to an autophosphorylation and binding to signaling adaptor proteins, like insulin receptor substrate (IRS)-l and Shc, which activate the ERK and PI3Kinase pathways.

Finally, high insulin levels can increase ovarian, and possibly also adrenal, androgen synthesis, and can cause the development of the polycystic ovary syndrome in some genetically susceptible pre-menopausal women (102). PCOS is characterized by ovarian hyperandrogenism and chronic anovulation, which results in continuous estrogen stimulation of the endometrium unopposed by progesterone (103). In PCOS pre-menopausal women, ovarian hyperandrogenism likely increases risk of endometrial cancer by decreasing local uterine IGFBP-1 synthesis, which in turn increases bio-availability of IGF-1, favoring tumor formation (104). Polycystic ovary syndrome and obesity are both associated with increased risk of endometrial cancer in pre and postmenopausal women, respectively $(73,105)$, and share mechanistic pathways that overlap between the estrogen, progesterone, androgen, and IGF systems.

Breast cancer risk and most established risk factors for endometrial cancer, such as early menarche, late menopause and obesity, probably act through pathways reflecting greater life-time exposure to estrogens. At a molecular level, estrogen actions are mediated by the estrogen receptors (ERalpha or ERbeta). The ER genomic actions involve its role as a transcription factor by binding directly to DNA through estrogen response elements, or by tethering to DNA through interaction with other proteins. However, estrogen can also exhibit pleiotropic effects trough nongenomic interactions with growth factor signaling pathways, including the phosphatidylinositol 3-kinase (PI3K)/Akt and the mitogenic-activated protein kinase pathways (106). Thus, besides ER is predominantly localized in the nucleus in steroid-deprived MCF-7 breast cancer cells, a substantial proportion is translocated to the plasma membrane upon E2 stimulation, contributing to growth factor receptor signaling.

\section{Obesity inflammation and cancer}

A causal relationship between cancer and inflammation is suspected for thousands of years. Galen was the first to note the relationship and Virchow, in the $19^{\text {th }}$ century, demonstrated that leukocytes were present in malignant tissues, claiming that tumors arise from chronic inflammation sites (107). Chronic infection and the consecutive inflammation that occurs may affect normal tissue cells, transforming these cells and might even affect tumors cells trough interaction with surrounding cells. Cancer deaths $(15 \%-20 \%)$ can be linked to inflammation and infection. For example, the major risk factors for hepatocellular carcinoma (HCC) are hepatitis B virus (HBV) and hepatitis $\mathrm{C}$ virus (HCV) chronic infections, and most gastric cancers are associated with Helicobacter pylori infections (108). Ulcerative colitis and other inflammatory bowel diseases are thought to increase the risk of colorectal cancer (109), and irritation and inflammation of airways by airborne particles and tobacco smoke might be important promoters of lung carcinogenesis (110).

In parallel, there is a large amount of evidence that links obesity, inflammation and the development of insulin resistance $(111,112)$. In obese adipose tissue there is macrophage recruitment, which, in turn, results in a pro-inflammatory state. Macrophages that are infiltrated in other tissues are known to secrete large amounts of tumor-necrosis factor (TNF), leading to a chronic inflammatory state with impaired triglyceride deposition and increased lipolysis, the excess of circulating triglyceride and free fatty acids results in disruption of normal metabolic functions such as mitochondrial oxidative phosphorylation and insulin-stimulated glucose transport, thus triggering insulin resistance.

Serine phosphorylation of IRS are major mechanisms that suppresses the insulin pathway leading to insulin resistance (113). In this regard, JNK, a member of the MAP kinase family that can be activated by TNFalpha, might serve as a feedback inhibitor during insulin stimulation. JNK activation induces inhibitory serine 307 (Ser307) phosphorylation of IRS-1. Ser307 is located next to the phosphotyrosine-binding (PTB) domain in IRS- 1 and its phosphorylation inhibits the interaction of the PTB domain with the phosphorylated NPEY motif in the activated IR, causing insulin resistance (114). Previous studies suggest that, in addition to JNK, IKKbeta phoshorylation also increases serine phosphorylation of IRS-1. Thus, the IKK complex appears to be another candidate that plays a key role in the phosphorylation of IRS- 1 and in the regulation of insulin sensitivity.

The nuclear factor kappaB (NF-kappaB) pathway plays a central role in inflammation and immunity. Transcription factors, which integrate stress signals and orchestrate immune responses known as NF- 
kappa $\mathrm{B}$ proteins, have recently been linked to the hallmarks of carcinogenesis, and recent experimental studies have demonstrated the mechanistic pathways by which NF-kappaB signaling (Figure 2) and JNK contributes to these aspects $(115,116)$. Greten and cols. (115) utilized the IKKbeta conditional knockout to test the role of the NF-kappaB activation pathway in controlling tumorigenesis in a colitis-associated model for cancer. In another related study, Maeda and cols. (116) showed that loss of IKKbeta in hepatocytes actually promoted chemical-induced hepatocarcinogenesis through a mechanism involving enhanced ROS production and JNK activation with associated cell death, leading to a compensatory response in surviving hepatocytes.

The consistent results from epidemiologic studies linking adiposity and the risk of several adult cancers turns plausible the hypothesis that the molecular mechanisms of carcinogenesis may be mediated by inflam- matory pathways. In face of the striking prevalence of obesity, understanding the exact molecular mechanisms connecting the two may be crucial to the treatment of this pathology.

\section{CONCLUSION}

In several studies, obesity has been associated with risk and prognosis for various cancers, and several mechanisms have been proposed to explain the links between obesity and cancer. Confirmation of the role of obesity on cancer risk and prognosis has emerged from clinical trials and meta-analyses in the last decades. Improvement of the knowledge of the pathophysiological mechanisms linking obesity and cancer would be necessary to establish Public Health interventions for reducing the impact of cancer.

Disclosure: No potential conflict of interest relevant to this article was reported.

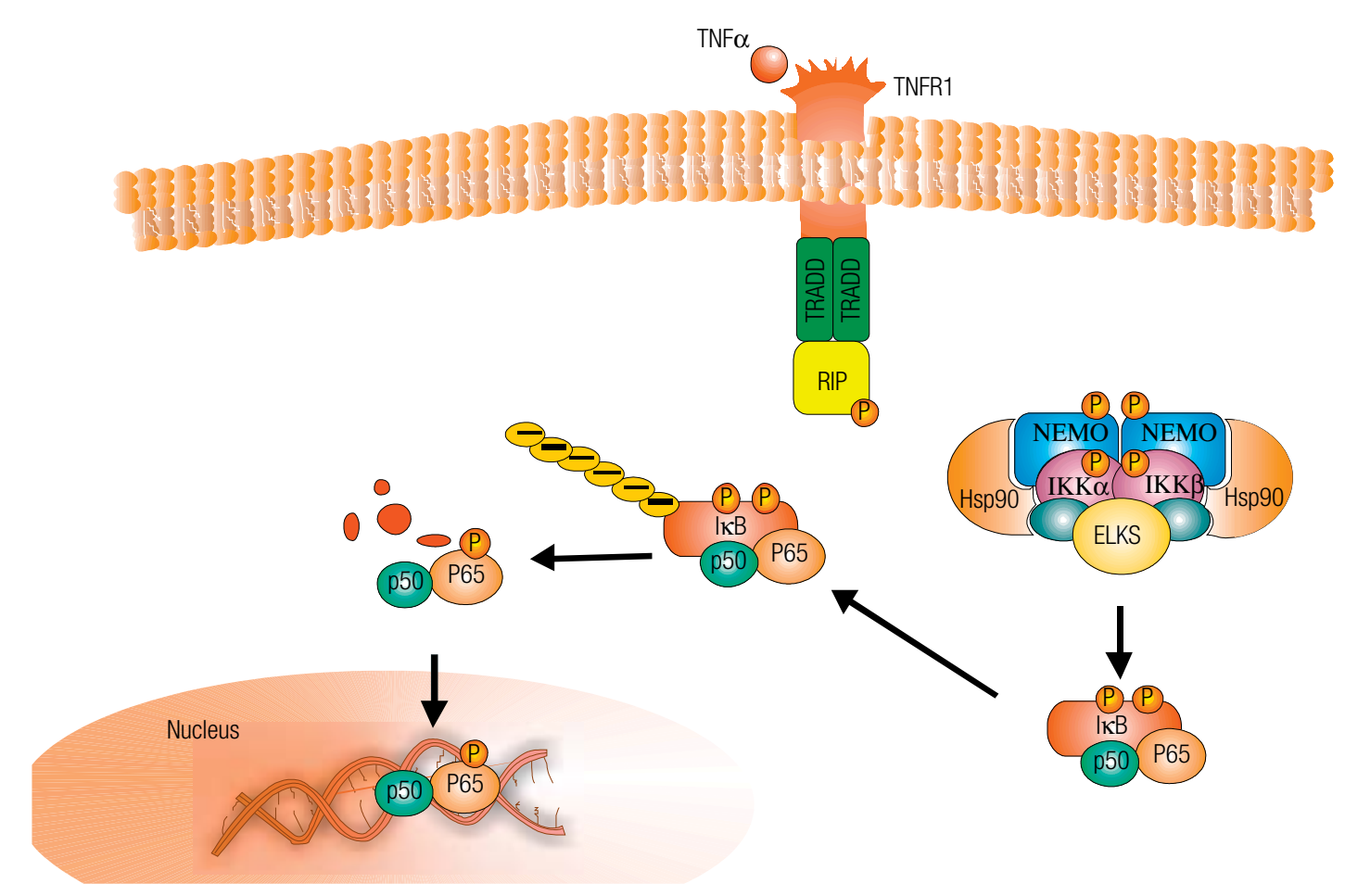

Figure 2. Activation of tumour-necrosis factor receptor 1 (TNFR) by binding of TNF $\alpha$ results in rapid assembly of complex I, which is composed of TNF receptor 1-associated protein (TRADD), receptor-interacting protein 1 (RIP1). This complex leads to activation of inhibitor of NFKB kinase (IKK). Activation of IKK leads to IKB phosphorylation and degradation that culminate in nuclear translocation of $\mathrm{NFKB}$. 


\section{REFERENCES}

1. Filozof C, Gonzalez C, Sereday M, Mazza C, Braguinsky J. Obesity prevalence and trends in Latin-American countries. Obes Rev. 2001;2(2):99-106.

2. Carvalheira JB, Saad MJ. [Insulin resistance/hyperinsulinemia associated diseases not included in the metabolic syndrome]. Arq Bras Endocrinol Metabol. 2006;50(2):360-7. Epub 2006 May 23. Review. Portuguese.

3. den $C L$, Carroll MD, Curtin LR, McDowell MA, Tabak CJ, Flegal KM. Prevalence of overweight and obesity in the United States, 1999-2004. JAMA. 2006;295(13):1549-55.

4. IARC - International Agency for Research on Cancer Working Group on the Evaluation of Cancer-Preventive Strategies. Weight control and physical activity. Lyon, France: IARC Press; 2002.

5. WCRF - World Cancer Reserach Fund. Food, nutrition, physical activity, and the prevention of cancer: a global perspective. Washington: American Institute for Cancer Research; 2007.

6. Reeves GK, Pirie K, Beral V, Green J, Spencer E, Bull D. Cancer incidence and mortality in relation to body mass index in the Million Women Study: cohort study. BMJ. 2007;335(7634):1134. Epub 2007 Nov 6.

7. Renehan AG, Tyson M, Egger M, Heller RF, Zwahlen M. Bodymass index and incidence of cancer: a systematic review and meta-analysis of prospective observational studies. Lancet. 2008;371(9612):569-78. Review.

8. Renehan AG, Roberts DL, Dive C. Obesity and cancer: pathophysiological and biological mechanisms. Arch Physiol Biochem. 2008;114(1):71-83. Review.

9. Calle EE, Rodriguez C, Walker-Thurmond K, Thun MJ. Overweight, obesity, and mortality from cancer in a prospectively studied cohort of U.S. adults. N Engl J Med. 2003;348(17):1625-38.

10. Yakar S, Nunez NP, Pennisi P, Brodt P, Sun H, Fallavollita L, et al. Increased tumor growth in mice with diet-induced obesity: impact of ovarian hormones. Endocrinology. 2006;147 (12):5826-34. Epub 2006 Sep 7.

11. Dirx MJ, Zeegers MP, Dagnelie PC, van den Bogaard T, van den Brandt PA. Energy restriction and the risk of spontaneous mammary tumors in mice: a meta-analysis. Int $\mathrm{J}$ Cancer. 2003;106(5):766-70.

12. Chow WH, Gridley G, Fraumeni JF Jr, Järvholm B. Obesity, hypertension, and the risk of kidney cancer in men. N Engl J Med. 2000;343(18):1305-11.

13. Larsson SC, Orsini N, Wolk A. Body mass index and pancreatic cancer risk: a meta-analysis of prospective studies. Int $\mathrm{J}$ Cancer. 2007;120(9):1993-8.

14. Pischon $T$, Lahmann $P H$, Boeing $H$, Friedenreich $C$, Norat T, Tjønneland $A$, et al. Body size and risk of colon and rectal cancer in the European Prospective Investigation Into Cancer and Nutrition (EPIC). J Natl Cancer Inst. 2006;98(13):920-31.

15. Jenab M, Riboli E, Cleveland RJ, Norat T, Rinaldi S, Nieters A, et al. Serum C-peptide, IGFBP-1 and IGFBP-2 and risk of colon and rectal cancers in the European Prospective Investigation into Cancer and Nutrition. Int J Cancer. 2007;121(2):368-76.

16. Sandhu MS, Dunger DB, Giovannucci EL. Insulin, insulin-like growth factor-I (IGF-I), IGF binding proteins, their biologic interactions, and colorectal cancer. J Natl Cancer Inst. 2002;94(136):972-80.

17. Renehan AG, Zwahlen M, Minder C, O'Dwyer ST, Shalet SM, Egger M. Insulin-like growth factor (IGF)-I, IGF binding protein-3, and cancer risk: systematic review and meta-regression analysis. Lancet. 2004;363(9418):1346-53.

18. Ma J, Pollak MN, Giovannucci E, Chan JM, Tao Y, Hennekens $\mathrm{CH}$, et al. Prospective study of colorectal cancer risk in men and plasma levels of insulin-like growth factor (IGF)-I and IGF-binding protein-3. J Natl Cancer Inst. 1999;91(7):620-5.
19. Wolpin BM, Meyerhardt JA, Chan AT, Ng K, Chan JA, Wu K, et al. Insulin, the insulin-like growth factor axis, and mortality in patients with nonmetastatic colorectal cancer. J Clin Oncol. 2009;27(2):176-85. Epub 2008 Dec 8.

20. Aaronson SA. Growth factors and cancer. Science. 1991;254(5035):1146-53. Review.

21. Kaaks R, Lukanova A. Energy balance and cancer: the role of insulin and insulin-like growth factor-I. Proc Nutr Soc. 2001;60(1):91106. Review.

22. Stattin P, Lukanova A, Biessy C, Söderberg S, Palmqvist R, Kaaks $R$, et al. Obesity and colon cancer: does leptin provide a link? Int J Cancer. 2004;109(1):149-52.

23. Carvalheira JB, Siloto RM, Ignacchitti I, Brenelli SL, Carvalho CR, Leite $A$, et al. Insulin modulates leptin-induced STAT3 activation in rat hypothalamus. FEBS Lett. 2001;500(3):119-24.

24. Björntorp P. Obesity. Lancet. 1997;350(9075):423-6.

25. Giovannucci E, Colditz GA, Stampfer MJ, Willett WC. Physical activity, obesity, and risk of colorectal adenoma in women (United States). Cancer Causes Control. 1996;7(2):253-63.

26. Stattin P, Palmqvist R, Söderberg S, Biessy C, Ardnor B, Hallmans $\mathrm{G}$, et al. Plasma leptin and colorectal cancer risk: a prospective study in Northern Sweden. Oncol Rep. 2003;10(6):2015-21.

27. Wei EK, Giovannucci E, Fuchs CS, Willett WC, Mantzoros CS. Low plasma adiponectin levels and risk of colorectal cancer in men: a prospective study. J Natl Cancer Inst. 2005;97(22):1688-94.

28. Lukanova A, Söderberg S, Kaaks R, Jellum E, Stattin P. Serum adiponectin is not associated with risk of colorectal cancer. Cancer Epidemiol Biomarkers Prev. 2006;15:401-2.

29. Huang Z, Hankinson SE, Colditz GA, Stampfer MJ, Hunter DJ, Manson JE, et al. Dual effects of weight and weight gain on breast cancer risk. JAMA. 1997;278(17):1407-11.

30. Travis RC, Key TJ. Oestrogen exposure and breast cancer risk. Breast Cancer Res. 2003;5(5):239-47.

31. Schairer C, Hill D, Sturgeon SR, Fears T, Pollak M, Mies C, et al. Serum concentrations of IGF-I, IGFBP-3 and c-peptide and risk of hyperplasia and cancer of the breast in postmenopausal women. Int J Cancer. 2004;108(5):773-9.

32. Toniolo P, Bruning PF, Akhmedkhanov A, Bonfrer JM, Koenig KL, Lukanova $A$, et al. Serum insulin-like growth factor-l and breast cancer. Int J Cancer. 2000;88(5):828-32.

33. Yang G, Lu G, Jin F, Dai Q, Best R, Shu XO, et al. Population-based, case-control study of blood C-peptide level and breast cancer risk. Cancer Epidemiol Biomarkers Prev. 2001;10(11):1207-11.

34. Hirose K, Toyama T, Iwata H, Takezaki T, Hamajima N, Tajima K. Insulin, insulin-like growth factor-l and breast cancer risk in Japanese women. Asian Pac J Cancer Prev. 2003;4(3):239-46.

35. Hankinson SE, Willett WC, Colditz GA, Hunter DJ, Michaud DS, Deroo $B$, et al. Circulating concentrations of insulin-like growth factor-I and risk of breast cancer. Lancet. 1998;351(9113):1393-6.

36. Goodwin PJ, Ennis M, Pritchard KI, Trudeau ME, Koo J, HartwickW, et al. Insulin-like growth factor binding proteins 1 and 3 and breast cancer outcomes. Breast Cancer ResTreat. 2002;74(1):65-76.

37. Vona-Davis L, Rose DP. Adipokines as endocrine, paracrine, and autocrine factors in breast cancer risk and progression. Endocr Relat Cancer. 2007;14(2):189-206.

38. Miyoshi Y, Funahashi T, Kihara S, Taguchi T, Tamaki Y, Matsuzawa $Y$, et al. Association of serum adiponectin levels with breast cancer risk. Clin Cancer Res. 2003;9(15):5699-704.

39. Mantzoros C, Petridou E, Dessypris N, Chavelas C, Dalamaga M, Alexe DM, et al. Adiponectin and breast cancer risk. J Clin Endocrinol Metab. 2004;89(3):1102-7.

40. Kaaks R, Lukanova A, Kurzer MS. Obesity, endogenous hormones, and endometrial cancer risk: a synthetic review. Cancer Epidemiol Biomarkers Prev. 2002:11(12):1531-43. Review. 
41. Lukanova A, Lundin E, Micheli A, Arslan A, Ferrari P, Rinaldi $S$, et al. Circulating levels of sex steroid hormones and risk of endometrial cancer in postmenopausal women. Int $\mathrm{J}$ Cancer. 2004;108(3):425-32.

42. Lukanova A, Zeleniuch-Jacquotte A, Lundin E, Micheli A, ArsIan AA, Rinaldi $S$, et al. Prediagnostic levels of C-peptide, IGF-I, IGFBP $-1,-2$ and -3 and risk of endometrial cancer. Int $\mathrm{J}$ Cancer. 2004;108(2):262-8.

43. Nicodemus KK, Sweeney C, Folsom AR. Evaluation of dietary, medical and lifestyle risk factors for incident kidney cancer in postmenopausal women. Int J Cancer. 2004;108(1):115-21.

44. Bergstrom A, Hsieh CC, Lindblad P, Lu CM, Cook NR, Wolk A. Obesity and renal cell cancer-a quantitative review. $\mathrm{Br} \mathrm{J}$ Cancer. 2001;85(7):984-90.

45. Pischon T, Lahmann PH, Boeing H, Tjonneland A, Halkjaer J, Overvad $K$, et al. Body size and risk of renal cell carcinoma in the European Prospective Investigation into Cancer and Nutrition (EPIC). Int J Cancer. 2006;118(3):728-38.

46. Lindblad P, Chow WH, Chan J, Bergström A, Wolk A, Gridley G, et al. The role of diabetes mellitus in the aetiology of renal cell cancer. Diabetologia. 1999;42(1):107-12.

47. Spyridopoulos TN, Petridou ET, Skalkidou A, Dessypris N, Chrousos GP, Mantzoros CS. Low adiponectin levels are associated with renal cell carcinoma: a case-control study. Int J Cancer. 2007;120(7):1573-8

48. Pera M, Manterola C, Vidal O, Grande L. Epidemiology of esophageal adenocarcinoma. J Surg Oncol. 2005;92(3):151-9.

49. Kubo A, Corley DA. Body mass index and adenocarcinomas of the esophagus or gastric cardia: a systematic review and metaanalysis. Cancer Epidemiol Biomarkers Prev. 2006;15(5):872-8.

50. Abnet CC, Freedman ND, Hollenbeck AR, Fraumeni JF Jr, Leitzmann $\mathrm{M}$, Schatzkin A. A prospective study of BMI and risk of oesophageal and gastric adenocarcinoma. Eur $\mathrm{J}$ Cancer. 2008:44(3):465-71.

51. Corley DA, Kubo A, Zhao W. Abdominal obesity and the risk of esophageal and gastric cardia carcinomas. Cancer Epidemiol Biomarkers Prev. 2008;17(2):352-8.

52. Hampel H, Abraham NS, El-Serag HB. Meta-analysis: obesity and the risk for gastroesophageal reflux disease and its complications. Ann Intern Med. 2005;143(3):199-211.

53. Giovannucci E, Michaud D. The role of obesity and related metabolic disturbances in cancers of the colon, prostate, and pancreas. Gastroenterology. 2007;132(6):2208-25.

54. Samanic C, Gridley G, Chow WH, Lubin J, Hoover RN, Fraumeni JF Jr. Obesity and cancer risk among white and black United States veterans. Cancer Causes Control. 2004;15(1):35-43.

55. Luo J, Margolis KL, Adami HO, LaCroix A, YeW. Obesity and risk of pancreatic cancer among postmenopausal women: the Women's Health Initiative (United States). Br J Cancer. 2008;99(3):527-31. Epub 2008 Jul 15.

56. Gapstur SM, Gann PH, Lowe W, Liu K, Colangelo L, Dyer A. Abnormal glucose metabolism and pancreatic cancer mortality. JAMA. 2000;283(19):2552-8.

57. Wolpin BM, Michaud DS, Giovannucci EL, Schernhammer ES, Stampfer MJ, Manson JE, et al. Circulating insulin-like growth factor axis and the risk of pancreatic cancer in four prospective cohort. Br J Cancer. 2007;97(1):98-104. Epub 2007 May 29.

58. Maclnnis RJ, English DR. Body size and composition and prostate cancer risk: systematic review and meta-regression analysis. Cancer Causes Control. 2006;17(8):989-1003.

59. Potischman N, Swanson CA, Siiteri P, Hoover RN. Reversal of relation between body mass and endogenous estrogen concentrations with menopausal status. J Natl Cancer Inst. 1996;88(11):756-8.
60. Chan JM, Stampfer MJ, Giovannucci E, Gann PH, Ma J, Wilkinson $\mathrm{P}$, et al. Plasma insulin-like growth factor-I and prostate cancer risk: a prospective study. Science. 1998;279(5350):563-6.

61. Larsson SC, Wolk A. Obesity and the risk of gallbladder cancer: a meta-analysis. Br J Cancer. 2007;96(9):1457-61.

62. Caldwell SH, Crespo DM, Kang HS, Al-Osaimi AM. Obesity and hepatocellular carcinoma. Gastroenterology. 2004;127(5 Suppl 1):S97-103. Review.

63. Pan SY, Johnson KC, Ugnat AM, Wen SW, Mao Y. Association of obesity and cancer risk in Canada. Am J Epidemiol. 2004;159(3):259-68.

64. Lahmann PH, Hoffmann K, Allen N, van Gils $\mathrm{CH}$, Khaw KT, Tehard $B$, et al. Body size and breast cancer risk: findings from the European Prospective Investigation into Cancer and Nutrition (EPIC). Int J Cancer. 2004;111(5):762-71.

65. Olsen CM, Green AC, Whiteman DC, Sadeghi S, Kolahdooz F, Webb PM. Obesity and the risk of epithelial ovarian cancer: a systematic review and meta-analysis. Eur J Cancer. 2007;43(4):690709. Epub 2007 Jan 12

66. Olsen CM, Nagle CM, Whiteman DC, Purdie DM, Green AC, Webb PM. Body size and risk of epithelial ovarian and related cancers: a population-based case-control study. Int J Cancer. 2008;123(2):450-6.

67. Engeland A, Tretli S, Hansen S, BjørgeT. Height and body mass index and risk of lymphohematopoietic malignancies in two million Norwegian men and women. Am J Epidemiol. 2007;165(1):44-52. Epub 2006 Oct 13.

68. Larsson SC, Wolk A. Body mass index and risk of multiple myeloma: a meta-analysis. Int J Cancer. 2007;121(11):2512-6.

69. Druker BJ. Imatinib as a paradigm of targeted therapies. Adv Cancer Res. 2004;91:1-30.

70. McKeown-Eyssen G. Epidemiology of colorectal cancer revisited: are serum triglycerides and/or plasma glucose associated with risk? Cancer Epidemiol Biomarkers Prev. 1994;3(8):687-95.

71. Giovannucci E. Insulin and colon cancer. Cancer Causes Control. 1995;6(2):164-79. Review.

72. Giovannucci E. Nutrition, insulin, insulin-like growth factors and cancer. Horm Metab Res. 2003;35(11-12):694-704.

73. Calle EE, Kaaks R. Overweight, obesity and cancer: epidemiological evidence and proposed mechanisms. Nat Rev Cancer. 2004;4(8):579-91.

74. Allen NE, Appleby PN, Kaaks R, Rinaldi S, Davey GK, Key TJ. Lifestyle determinants of serum insulin-like growth-factor-I (IGF-I), $\mathrm{C}$-peptide and hormone binding protein levels in British women. Cancer Causes Control. 2003;14(1):65-74.

75. Holmes MD, Pollak MN, Hankinson SE. Lifestyle correlates of plasma insulin-like growth factor I and insulin-like growth factor binding protein 3 concentrations. Cancer Epidemiol Biomarkers Prev. 2002;11(9):862-7.

76. MyalY, Shiu RP, Bhaumick B, Bala M. Receptor binding and growth-promoting activity of insulin-like growth factors in human breast cancer cells (T-47D) in culture. Cancer Res. 1984;44(12 Pt 1):5486-90.

77. Wu Y, Cui K, Miyoshi K, Hennighausen L, Green JE, Setser J, et al. Reduced circulating insulin-like growth factor I levels delay the onset of chemically and genetically induced mammary tumors. Cancer Res. 2003;63(15):4384-8.

78. Pollak M, Blouin MJ, Zhang JC, Kopchick JJ. Reduced mammary gland carcinogenesis in transgenic mice expressing a growth hormone antagonist. Br J Cancer. 2001;85(3):428-30.

79. Creighton CJ, Casa A, Lazard Z, Huang S, Tsimelzon A, Hilsenbeck $S G$, et al. Insulin-like growth factor-l activates gene transcription programs strongly associated with poor breast cancer prognosis. J Clin Oncol. 2008;26:4078-85. 
80. Carvalheira JB, Zecchin HG, Saad MJ. [Vias de sinalização da insulina]. Arq Bras Endocrinol Metabol. 2002;46(4):419-25.

81. Moore T, Beltran L, Carbajal S, Strom S, Traag J, Hursting SD, et al. Dietary energy balance modulates signaling through the akt/ mammalian target of rapamycin pathways in multiple epithelial tissues. Cancer Prev Res. 2008;1(1):65-76. Epub 2008 Mar 31.

82. Cantley LC. The phosphoinositide 3-kinase pathway. Science. 2002:296(5573):1655-7.

83. Inoki K, Li Y, Zhu T, Wu J, Guan KL. TSC2 is phosphorylated and inhibited by Akt and suppresses mTOR signalling. Nat Cell Biol. 2002;4(9):648-57.

84. Garami A, Zwartkruis FJ, Nobukuni T, Joaquin $M$, Roccio $M$, Stocker $\mathrm{H}$, et al. Insulin activation of Rheb, a mediator of mTOR/ S6K/4E-BP signaling, is inhibited by TSC1 and 2. Mol Cell. 2003;11(6):1457-66.

85. Hay N, Sonenberg N. Upstream and downstream of mTOR. Genes Dev. 2004;18(16):1926-45.

86. McManus EJ, Alessi DR. TSC1-TSC2: a complex tale of PKB-mediated S6K regulation. Nat Cell Biol. 2002;4(9):E214-6.

87. Roux PP, Ballif BA, Anjum R, Gygi SP, Blenis J.Tumor-promoting phorbol esters and activated Ras inactivate the tuberous sclerosis tumor suppressor complex via p90 ribosomal S6 kinase. Proc Natl Acad Sci U S A. 2004;101(37):13489-94. Epub 2004 Sep 1.

88. Inoki K, Zhu T, Guan KL. TSC2 mediates cellular energy response to control cell growth and survival. Cell. 2003;115(5):577-90.

89. Harrington LS, Findlay GM, Lamb RF. Restraining PI3K: mTOR signalling goes back to the membrane. Trends Biochem Sci. 2005;30(1):35-42.

90. Fantl WJ, Muslin AJ, Kikuchi A, Martin JA, MacNicol AM, Gross RW, et al. Activation of Raf-1 by 14-3-3 proteins. Nature. 1994;371(6498):612-4.

91. Blagosklonny MV. Hsp-90-associated oncoproteins: multiple targets of geldanamycin and its analogs. Leukemia. 2002;16(4):455-62.

92. Kyriakis JM, App $H$, Zhang XF, Banerjee $P$, Brautigan DL, Rapp UR, et al. Raf-1 activated MAP kinase kinase. Nature. 1992;358(6385):417-21.

93. Yoon S, Seger R. The extracellular signal-regulated kinase: multiple substrates regulate diverse cellular functions. Growth Factors. 2006;24(1):21-44.

94. Murphy LO, Blenis J. MAPK signal specificity: the right place at the right time. Trends Biochem Sci. 2006;31(5):268-75. Epub 2006 Apr 17.

95. Key TJ, Appleby PN, Reeves GK, Roddam A, Dorgan JF, Longcope $C$, et al. Body mass index, serum sex hormones, and breast cancer risk in postmenopausal women. J Natl Cancer Inst. 2003;95(16):1218-26.

96. Pugeat M, Crave JC, Elmidani M, Nicolas MH, Garoscio-Cholet $M$, Lejeune $\mathrm{H}$, et al. Pathophysiology of sex hormone binding globulin (SHBG): relation to insulin. J Steroid Biochem Mol Biol. 1991;40(4-6):841-9.

97. McTiernan A, Rajan KB, Tworoger SS, Irwin M, Bernstein L, Baumgartner $\mathrm{R}$, et al. Adiposity and sex hormones in postmenopausal breast cancer survivors. J Clin Oncol. 2003;21(10):1961-6.

98. Fortunati N, Fissore F, Fazzari A, Piovano F, Catalano MG, Becchis $\mathrm{M}$, et al. Estradiol induction of cAMP in breast cancer cells is mediated by foetal calf serum (FCS) and sex hormone-binding globulin (SHBG). J Steroid Biochem Mol Biol. 1999;70(1-3):73-80.

99. Fortunati N, Fissore F, Fazzari A, Becchis M, Comba A, Catalano $M G$, et al. Sex steroid binding protein exerts a negative control on estradiol action in MCF-7 cells (human breast cancer) through cyclic adenosine 3 ',5'-monophosphate and protein kinase A. Endocrinology. 1996;137(2):686-92.

100. Catalano MG, Frairia R, Boccuzzi G, Fortunati N. Sex hormonebinding globulin antagonizes the anti-apoptotic effect of estradiol in breast cancer cells. Mol Cell Endocrinol. 2005;230(1-2):31-7.

101. Lee AV, Jackson JG, Gooch JL, Hilsenbeck SG, Coronado-Heinsohn E, Osborne CK, et al. Enhancement of insulin-like growth factor signaling in human breast cancer: estrogen regulation of insulin receptor substrate-1 expression in vitro and in vivo. Mol Endocrinol. 1999;13(5):787-96.

102. Dunaif A. Insulin resistance and the polycystic ovary syndrome: mechanism and implications for pathogenesis. Endocr Rev. 1997;18(6):774-800.

103. Ehrmann DA, Barnes RB, Rosenfield RL. Polycystic ovary syndrome as a form of functional ovarian hyperandrogenism due to dysregulation of androgen secretion. Endocr Rev. 1995;16(3):32253. Review.

104. Druckmann R, Rohr UD. IGF-1 in gynaecology and obstetrics: update 2002. Maturitas. 2002;41 Suppl 1:S65-83.

105. Colangelo LA, Gapstur SM, Gann PH, Dyer AR, Liu K. Colorectal cancer mortality and factors related to the insulin resistance syndrome. Cancer Epidemiol Biomarkers Prev. 2002;11(4):385-91.

106. Schiff R, Massarweh SA, Shou J, Bharwani L, Mohsin SK, Osborne CK. Cross-talk between estrogen receptor and growth factor pathways as a molecular target for overcoming endocrine resistance. Clin Cancer Res. 2004;10(1 Pt2):S331-6.

107. Balkwill F, Mantovani A. Inflammation and cancer: back to Virchow? Lancet. 2001;357(9255):539-45.

108. Roder DM. The epidemiology of gastric cancer. Gastric Cancer. 2002;5 Suppl 1:5-11.

109. Ekbom A. Risk of cancer in ulcerative colitis. J Gastrointest Surg. 1998;2(4):312-3. Review.

110. Dhala A, Pinsker K, Prezant DJ. Respiratory health consequences of environmental tobacco smoke. Med Clin North Am. 2004;88(6):1535-52, xi.

111. Hotamisligil GS, Shargill NS, Spiegelman BM. Adipose expression of tumor necrosis factor-alpha: direct role in obesity-linked insulin resistance. Science. 1993;259(5091):87-91.

112. Tsukumo DM, Carvalho-Filho MA, Carvalheira JB, Prada PO, Hirabara SM, Schenka AA, et al. Loss-of-function mutation in Toll-like receptor 4 prevents diet-induced obesity and insulin resistance. Diabetes. 2007;56(8):1986-98. Epub 2007 May 22.

113. Greene MW, Sakaue H, Wang L, Alessi DR, Roth RA. Modulation of insulin-stimulated degradation of human insulin receptor substrate-1 by Serine 312 phosphorylation. J Biol Chem. 2003:278(10):8199-211. Epub 2003 Jan 1.

114. Aguirre V, Werner ED, Giraud J, Lee YH, Shoelson SE, White MF Phosphorylation of Ser307 in insulin receptor substrate-1 blocks interactions with the insulin receptor and inhibits insulin action. $J$ Biol Chem. 2002;277(2):1531-7. Epub 2001 Oct 17.

115. Greten FR, Eckmann L, Greten TF, Park JM, Li ZW, Egan LJ, et al. IKKbeta links inflammation and tumorigenesis in a mouse model of colitis-associated cancer. Cell. 2004;118(3):285-96.

116. Maeda S, Kamata $H$, Luo JL, Leffert H, Karin M. IKKbeta couples hepatocyte death to cytokine-driven compensatory proliferation that promotes chemical hepatocarcinogenesis. Cell. 2005;121(7):977-90. 